\title{
Hollow Cylinder Simulation Experiments of Galleries in Boom Clay Formation
}

\author{
Vincent Labiouse • Claire Sauthier • \\ Shuang You
}

Received: 2 November 2012/Accepted: 4 November 2012/Published online: 15 February 2013

(C) Springer-Verlag Wien 2013

\begin{abstract}
In the context of nuclear waste disposal in clay formations, laboratory experiments were performed to study at reduced scale the excavation damaged zone (EDZ) induced by the construction of galleries in the Boom clay formation. For this purpose, thick-walled hollow cylindrical samples were subjected (after recovery of in situ stress conditions) to a decrease in the inner confining pressure aiming at mimicking a gallery excavation. X-ray computed tomography (XRCT) scans of the specimens were carried out through the testing cell before and after the mechanical unloading and allowed to quantify the displacements undergone by the clay as a result of the mechanical unloading. The deformation of the hollow cylinders and the inferred extent of the damaged zone around the central hole are found to depend on the orientation of the specimen with respect to the bedding planes and show a great similarity with in situ observations around galleries and boreholes at Mol URL in the Boom clay formation. In the experiments performed on samples cored parallel to the bedding, the damaged zone is not symmetrical with respect to the hole axis and extends more in the direction parallel to the bedding. It is the same for the radial convergence of the hole walls which is larger in the direction parallel to bedding than in the perpendicular one. In contrast, a test on a sample cored perpendicularly to the bedding did not show
\end{abstract}

TIMODAZ project co-funded by the European Commission and performed as part of the sixth EURATOM framework programme for nuclear research and training activities (2002-2006) under contract FI6W-CT-2007-036449.

V. Labiouse $(\bowtie) \cdot$ C. Sauthier $\cdot$ S. You

Rock Mechanics Laboratory (LMR), Ecole Polytechnique

Fédérale de Lausanne (EPFL), Lausanne, Switzerland

e-mail: vincent.labiouse@epfl.ch

URL: http://lmr.epfl.ch/ any ovalisation of the central hole after the mechanical unloading. These observations confirm the significance of the pre-existing planes of weakness (bedding planes) in Boom clay and the need for a correct consideration of the related mechanical anisotropy.

Keywords Hollow cylinder test - Model gallery excavation $\cdot$ Excavation damaged zone . X-ray computed tomography - Boom clay . Nuclear waste disposal

\section{Introduction}

\subsection{Nuclear Waste Disposal in Boom Clay}

Geological disposal in clay formations is a promising option for the long-term management of high level and long-lived radioactive waste and such host formations generally have in their natural state favourable barrier properties against the migration of radionuclides: very low permeability, low solute diffusion rates, good retention and sorption capacity for many radionuclides, self-sealing capacity due to swelling and creep (Blümling et al. 2007).

During the construction of disposal galleries, the stress redistribution will lead to the development of a so-called excavation damaged zone (EDZ). Its extent has to be controlled, not only to prevent collapses during construction, but as well to limit its influence on the repository performance. Indeed, due to the presence of several failure planes, the EDZ could be a preferential pathway for water and/or gas flow and thus could provide an alternate, possibly faster, path for the migration of radionuclides by advective flow instead of by diffusion into the intact clay formation. 
Within the sixth EURATOM framework program of the European community, the TIMODAZ project (thermal impact on the damaged zone around a radioactive waste disposal in clay host rocks) aimed at studying the fracturing and self-sealing processes that develop in the excavation damaged zone (EDZ) around disposal galleries for heatemitting radioactive waste and at assessing the impact of the thermal phase on their evolution. Three different potential geological formations for deep radioactive waste repositories were investigated in the project, i.e. the Boom, Opalinus and Callovo-Oxfordian clayey formations. In North Belgium, the Boom clay formation is potentially considered for the geological disposal of radioactive waste and has been the object of continuous investigations since the mid-seventies. It is a marine deposit of tertiary, Rupelian age (30 million years), gently dipping (1-2\%) towards the NNE (Mertens et al. 2004). At the Mol-Dessel nuclear site, where the clay is located at depths between 185 and $287 \mathrm{~m}$ below surface, an underground research facility (HADES-URF) is situated at a depth of $223 \mathrm{~m}$. The total vertical stress and pore water pressure at this level are about 4.5 and $2.2 \mathrm{MPa}$, respectively. In 2002, an $80 \mathrm{~m}$ long and $4.9 \mathrm{~m}$ diameter connecting gallery was constructed between a first facility built in the 1980s and second shaft excavated in 1999. In 2006-2007, another gallery so-called Praclay, $2.5 \mathrm{~m}$ in diameter and $45 \mathrm{~m}$ in length, was dug to study and demonstrate the suitability of Boom clay to host heat-emitting radioactive waste. To limit the extent of the EDZ, both galleries were constructed using a semi-mechanised technique, with a road header under the protection of a shield and the use of rings made of concrete segments that can be expanded against the excavated profile (wedge-block technique).

\subsection{Hollow Cylinder Testing}

Experiments on hollow cylinders can be carried out for both the characterisation of rock properties and the physical modelling at reduced scale of engineering applications. As concerns the first purpose, the combination of internal pressure, external pressure and axial load allows to subject samples to truly three-dimensional state of stress also called polyaxial $\left(\sigma_{1}>\sigma_{2}>\sigma_{3}>0\right)$ and to study their mechanical behaviour under a wide variety of stress paths (Hoskins 1969; Alsayed 2002). In low permeability materials, the use of hollow cylinder samples has the advantage to reduce the drainage path as compared to experiments on standard full cylinder specimens and consequently to speed up the equalisation of pore water pressures during sample resaturation and consolidation (Monfared et al. 2011). It also permits to reach a steady-state flow faster in radial permeability tests and to more easily achieve fully drained conditions when studying the thermo-hydro-mechanical behaviour of low permeability geomaterials.
The second application of hollow cylinders is the simulation of stress conditions around underground openings. Most of the experiments are performed in the petroleum engineering field to study the instabilities occurring around deep well bores in rocks during either their drilling (e.g. Santarelli and Brown 1989; Haimson and Kovacich 2003) or the oil production phase (Hosseini et al. 2006), but they are as well relevant in the tunnelling domain to study the damaged zone developing around tunnels and shafts towards an efficient design of their support (Ewy and Cook 1990). Experiments on thick-walled hollow cylinders of clay rocks were conducted by Marsden et al. (1996), Chen et al. (1998) and Abdulhadi et al. (2011) on, respectively, a smectite mudrock, a synthetic soft shale and re-sedimented Boston blue clay. All testing devices allow for independent control of the inner and outer confining pressures, pore water pressure and axial load. After saturation and consolidation of the sample, the borehole pressure is reduced to mimic the conditions during the drilling of petroleum boreholes or the excavation of tunnels.

Within the framework of the TIMODAZ project, the Rock Mechanics Laboratory of the EPFL, Switzerland, performed laboratory experiments to study at reduced scale the excavation damaged zone (EDZ) induced by the construction of galleries in the Boom clay formation. For this purpose, thick-walled hollow cylindrical samples were subjected (after recovery of in situ stress conditions) to a decrease in the inner confining pressure aiming at mimicking a gallery excavation. X-ray computed tomography (XRCT) scans of the specimens were carried out through the testing cell before and after the mechanical unloading and allowed to monitor the displacements undergone by the clay as a result of the mechanical unloading. After a short description of the testing device and procedure and some explanations about the image processing of the XRCT scans, the paper presents the results on Boom clay samples cored parallel and perpendicular to bedding. These laboratory data are then compared with in situ observations made during the construction of the connecting gallery and Praclay gallery at Mol URL.

The experimental findings from thick-walled hollow cylinders of Opalinus clay performed in the TIMODAZ project are presented and discussed in a companion paper (Labiouse and Vietor 2013).

\section{Simulation Experiments}

\subsection{Hollow Cylinder Samples and Testing Device}

The thick-walled hollow cylinders have an external diameter of $86 \mathrm{~mm}$, a central hole of $14 \mathrm{~mm}$ in diameter and a height of about $170 \mathrm{~mm}$. They are prepared from cores 
sampled with a double tube core barrel (flushing with compressed air) and preserved in a vacuum packed plastic film. The coaxial central hole is drilled in dry conditions after confinement of the specimen in two half-shells. Then, the upper and lower parts of the samples are glued to caps. Between them, the outer and inner surfaces of the specimens are covered by drains (geotextile) and neoprene jackets. Throughout the preparation, attention is paid to preserve as much as possible the original hydration state.

A new cell was designed and constructed. Because of the presence of a central hole in the specimen and the need for an independent control of the outer and inner confining pressures as well as of the outer and inner drain pressures, the experimental set-up differs from usual triaxial testing devices, i.e. necessity of an internal rubber membrane and of an inner drain in the central hole, need for four separate hydraulic circuits and pressure-volume controllers, use of special caps. A sketch of the experimental set-up is shown in Fig. 1. Moreover, in to allow a medical X-ray computed tomography device to scan the sample through the cell walls (see Sect. 2.3), the usual stainless steel body cell was replaced by an aluminium body cell to reduce the $\mathrm{X}$-ray attenuation.

\subsection{Testing Procedure}

The testing procedure was defined to simulate as well as possible at scale the in situ conditions and early stages of repository galleries, i.e. the excavation followed by an open drift period. After preparation and set-up in the cell, the thick-walled hollow cylinder samples were subjected to the following stages (Fig. 2):

1. Recovery of in situ stress conditions: preloading of the sample to prevent its swelling when it sucks in water, saturation of the inner and outer hydraulic circuits and drains with deaerated and demineralised water, loading of the sample up to the in situ stress conditions (total stress of 4.5 MPa and pore water pressure of 2.2 MPa) and finally consolidation (equilibrium of pore water pressures). This stage lasted for at least 3 weeks until the volumes measured at the various controllers reached a constant value.

2. Mechanical unloading: the confining pressure in the central hole $\sigma_{3 \text { int }}$ is reduced from 4.5 to $1 \mathrm{MPa}$ in $70 \mathrm{~min}$, while the outer confining pressure $\sigma_{3 \text { ext }}$ is kept constant at $4.5 \mathrm{MPa}$ and an undrained condition is imposed at the inner boundary (closure of a valve of the inner hydraulic circuit). The aim of this unloading is to model the extension stress path that develops during the construction of disposal galleries and to induce a damaged zone around the central hole, similarly to the excavation damaged zone observed around galleries.

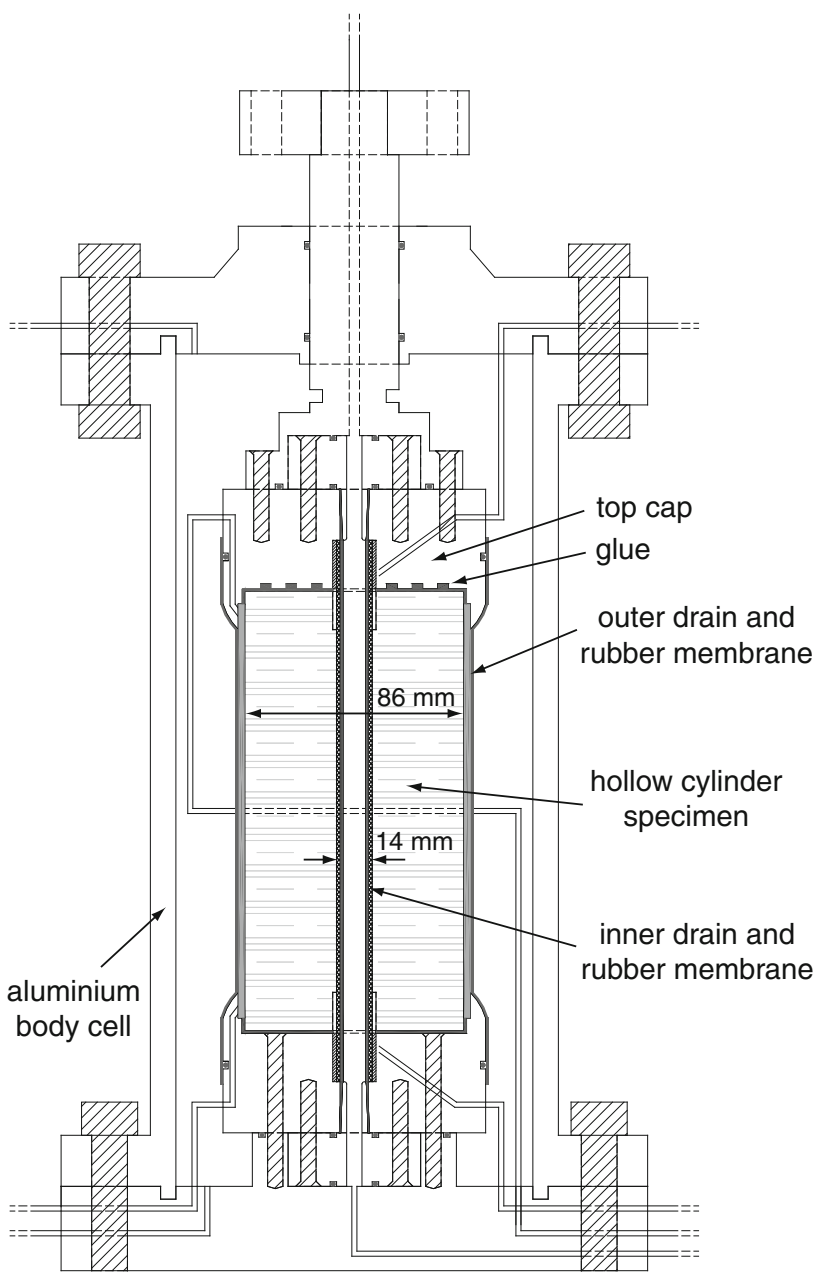

Fig. 1 Schematic of the testing device employed to perform the hollow cylinder simulation experiments

3. Drainage: during this stage, the inner confining and drain pressures are kept constant at, respectively, 1 and $0.1 \mathrm{MPa}$ (except for one test for which it was fortuitously imposed at $0.6 \mathrm{MPa}$ ). This stage of the simulation tests is particularly interesting to model the redistribution of pore water pressures in the massif after the construction of the repository galleries. Indeed, according to scaling laws, the time scale is equal to the square of the geometrical scale. As the central hole with a radius of $7 \mathrm{~mm}$ is corresponding to a $2.5 \mathrm{~m}$ diameter disposal gallery, the geometrical scale is equal to 178 and thus the time scale to 31,887 , which means that $1 \mathrm{~h}$ in the experiment corresponds to 3.65 years at full scale!

The above-described testing conditions are close to the conditions that will be experienced by the Boom clay formation around disposal galleries at Mol, but they do not match them perfectly. Indeed, the finite dimensions of the hollow cylinder samples obviously cannot represent the infinite extent of the host formation around galleries and 
Fig. 2 Successive stages of the hollow cylinder simulation experiments. Indicative evolution of external cell pressure $\sigma_{3 \text { ext }}$, central hole pressure $\sigma_{3 \text { int }}$, outer drain pressure $u_{\mathrm{ext}}$ and inner drain pressure $u_{\text {int }}$. The time and duration of the stages varied from one test to the other

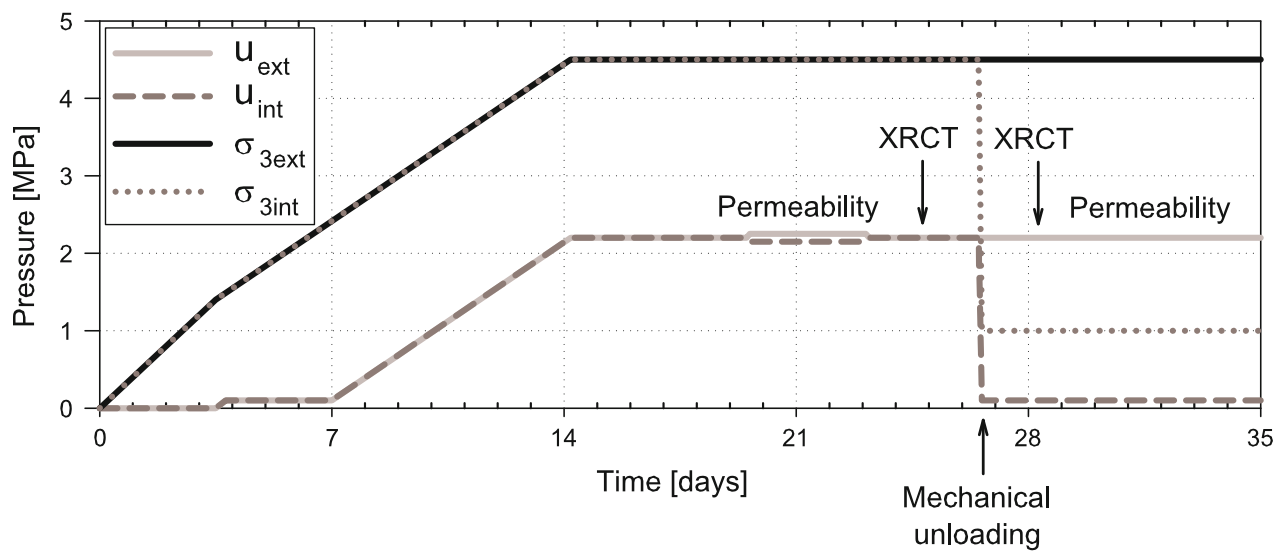

therefore the laboratory situation is not fully similar at scale to the field situation. More, the anisotropic in situ stress conditions (coefficient of earth pressure at rest $K_{0}=0.9$ ) are not reproducible in the hollow cylinder tests (axisymmetric loading) and the plane-strain condition was not strictly fulfilled in the experiments, for lack of a fifth pressure-volume controller.

\subsection{Measurements}

To observe the changes induced around the central hole by the mechanical unloading without removing the sample from the testing cell, X-ray computed tomography (XRCT) was used. For this purpose, before and after the mechanical unloading, the cell was transported with its valves closed to the Cantonal Hospital CHUV (Centre Hospitalier Universitaire Vaudois) and scanned at the Department of Diagnostic and Interventional Radiology (You et al. 2010). The scans lasted for about $15 \mathrm{~min}$ and provided about 600 reconstructed density maps of $512 \times 512$ pixels each with a range of 65,536 grey levels. Figure 3 illustrates a density map perpendicular to the cylinder axis located at mid-height of sample 13A, as obtained before and after mechanical unloading. Despite the medium resolution of the medical scanner (voxel size of $0.6 \times 0.215 \times 0.215 \mathrm{~mm}$ and effective resolution limited to about $0.5 \mathrm{~mm}$ ), the technique was found interesting for indirect imaging of rock samples inside the testing cell and even for quantitative analyses of the displacement undergone by the clay during testing. The quality of the images was considerably enhanced using an aluminium body cell, which far less attenuates the X-rays through the testing device, when compared with the stainless steel body of usual triaxial cells.

Permeability measurements were as well performed before and after the mechanical unloading to check a potential change in flow properties related to the development of a damaged zone around the central hole. A radial convergent fluid flow is generated in the sample by imposing a constant pressure difference between the pressure-volume controllers connected to the outer and inner hydraulic circuits, i.e. 100 and $2,100 \mathrm{kPa}$, respectively, before and after the mechanical unloading (Fig. 2). The permeability measurements are carried out when a steady state flow is reached in the sample, i.e. when the water fluxes entering and leaving the sample are equal (condition actually fulfilled after 2-3 days of flow). The obtained hydraulic conductivity value is an average value for the whole specimen; it includes the anisotropic permeability of Boom clay (about $2 \times 10^{-12}$ and $4 \times 10^{-12} \mathrm{~m} / \mathrm{s}$ in the directions perpendicular and parallel to bedding, respectively) and the possible change in the damaged zone developing around the central hole.

\subsection{Image Processing}

A comparison of the X-ray tomography scans before and after mechanical unloading allows a first qualitative observation of the deformation of the central hole. Moreover, due to the presence in the clayey material of pyrite inclusions that are well discernible in the CT scans (because of their higher density), quantitative analyses were performed using a particle tracking technique. After identification of the pyrite inclusions located in the central part of the specimen (to avoid the boundary effects of the upper and lower caps), their displacement is computed by comparing their position in the $\mathrm{CT}$ scans performed before and after mechanical unloading (Fig. 4). Then, the data were processed to determine the displacement profiles along diameters parallel, perpendicular and at $45^{\circ}$ with respect to bedding, allowing to evidence the anisotropic response of the clay related to its bedding planes. This was achieved by grouping the particles located into three azimuthal sectors defined by two lines at $\pm 15^{\circ}$ to the diameters, respectively, parallel, perpendicular and at $45^{\circ}$ to the bedding planes orientation (Fig. 5).

The X-ray tomography images were as well analysed using a full-field digital image correlation (DIC) method. The results are encouraging and in general agreement with 


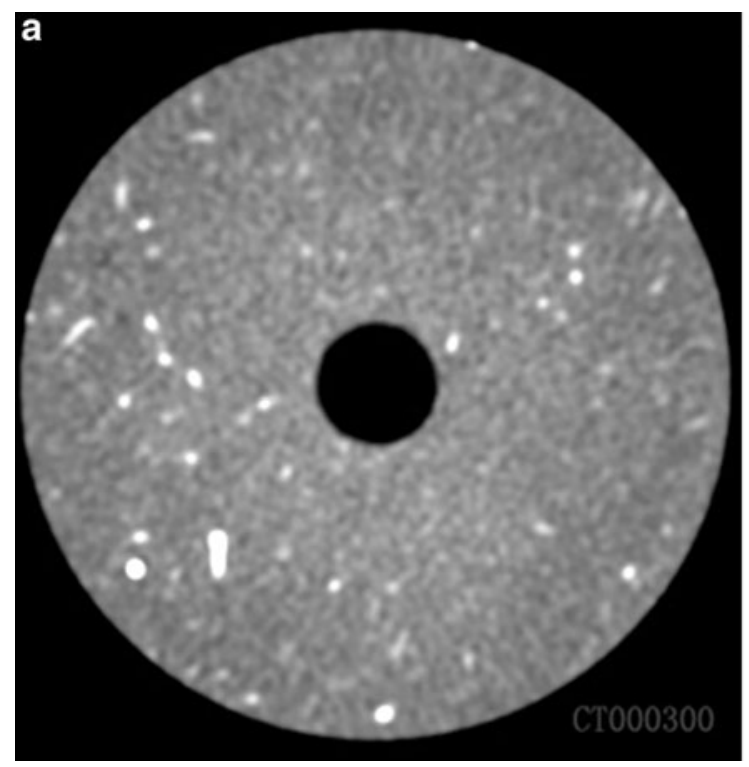

Fig. 3 Medium resolution X-ray computed tomography (XRCT) scans of the hollow cylinder specimen $13 \mathrm{~A}$ carried out through the testing cell before (a) and after (b) the mechanical unloading. Slice

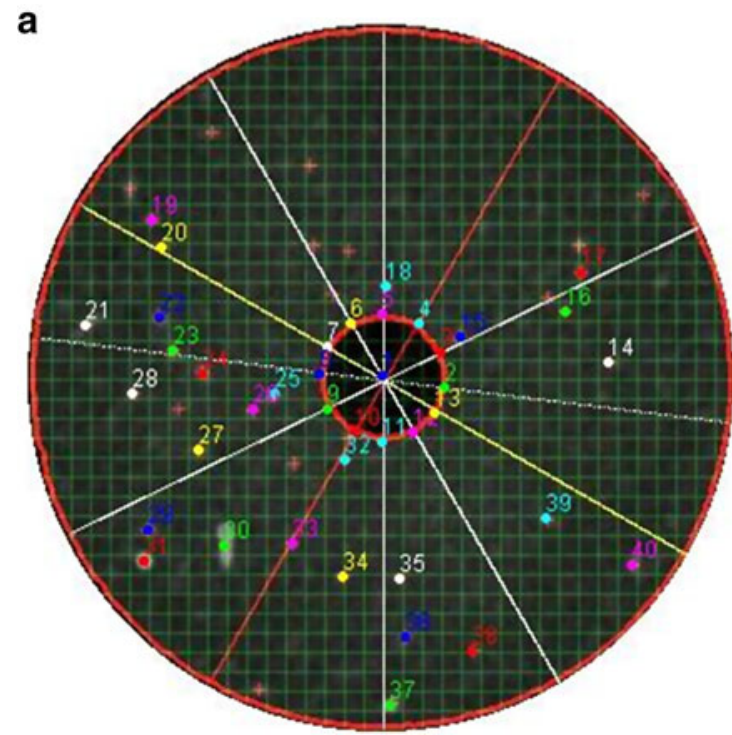

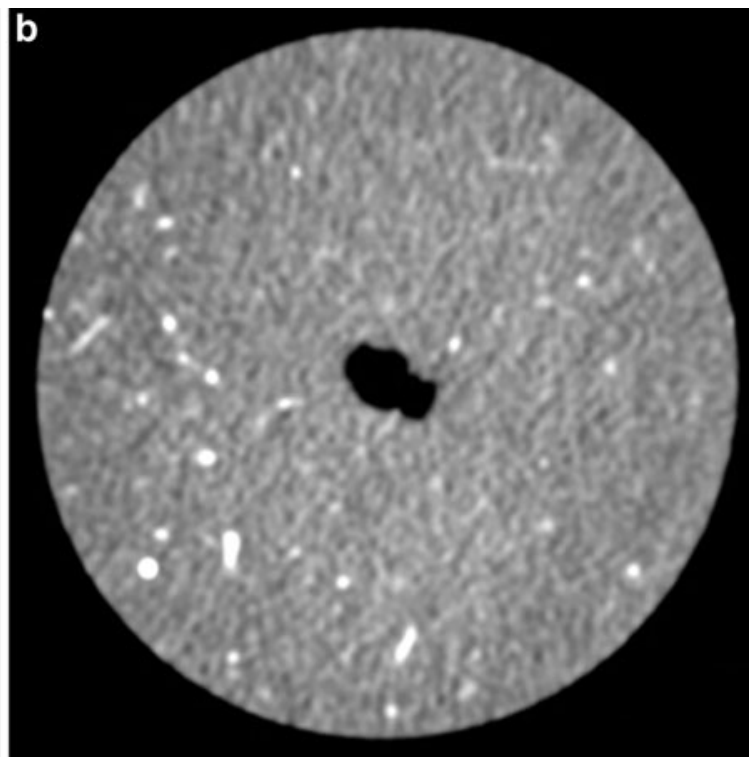

$\mathrm{N}^{\circ} 300$ perpendicular to the cylinder axis and located at mid-height. The well-discernible white spots are pyrite inclusions. Images courtesy of Lausanne Cantonal Hospital (CHUV)

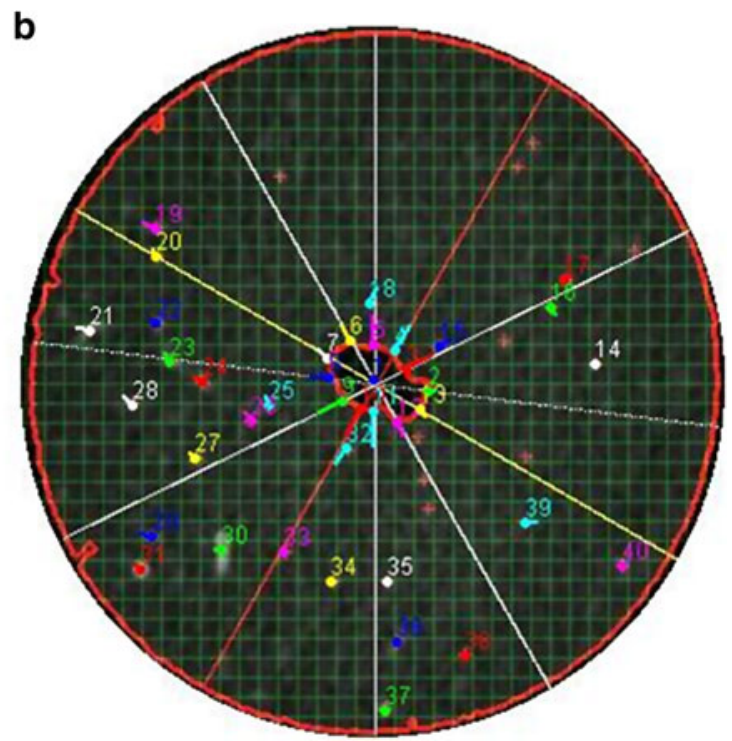

Fig. 4 Computation of pyrite inclusion displacement by means of a particle tracking technique comparing the XRCT images before (a) and after (b) the mechanical unloading. Example of processing illustrated on the slice $\mathrm{N}^{\circ} 300$ shown in Fig. 3

the displacements obtained with the particle tracking technique along the three considered directions.

\section{Experimental Results}

A first series of experiments performed to check the testing device and procedure did not succeed on account of leakage problems (puncturing of the internal membrane and poor water tightness of an O-ring). They were fixed by some adaptations of the testing device. The experimental study on Boom clay was carried out on samples from drill cores parallel to the bedding planes and on specimens cored perpendicularly to bedding in blocks retrieved during the construction of the PRACLAY gallery at Mol. For the latter, the coring direction was selected after a careful examination of the bedding plane orientation.

In Figs. 6 and 7 presented in the following section, the orientation of the bedding planes is represented by a set of parallel dashed lines. This orientation is actually hardly discernible in the XRCT images taken at Lausanne Cantonal Hospital, because of both the medium resolution of 


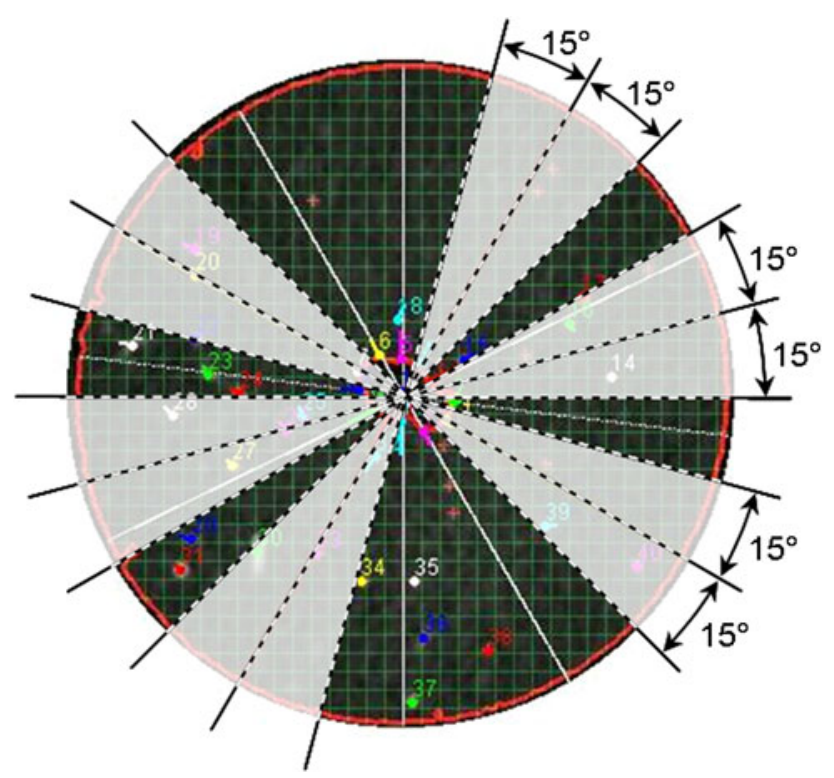

Fig. 5 Grouping of the pyrite inclusions located into three azimuthal sectors to plot the displacement profiles along diameters parallel, perpendicular and at $45^{\circ}$ with respect to bedding. Example of processing illustrated on the slice $\mathrm{N}^{\circ} 300$ shown in Fig. 3

the medical scanner and the extremely thin lamination of the clay. Instead, the bedding plane orientation was inferred from a visual inspection of the sample prior to testing and referenced with respect to a set of metallic rod marks placed around the hollow cylinder (Fig. 7). The orientation was as well confirmed after testing by letting the sample dry at room atmosphere and observing the preferential development of desiccation cracks along the bedding planes.

\subsection{Samples Cored Parallel to Bedding}

\subsection{1 $13 A$}

After the mechanical unloading consisting in a decrease of the borehole pressure from 4.5 to $1 \mathrm{MPa}$ in $70 \mathrm{~min}$, the sample 13A was let to drain for about $4 \mathrm{~h}$ under inner confining and drain pressures of, respectively, 1,000 and $100 \mathrm{kPa}$ and scanned in the testing cell at the cantonal hospital (about $1 \mathrm{~h}$ later). Figure 6 illustrates computed tomography slices of the sample inside the cell obtained before and after the mechanical unloading. A very clear oval-shaped deformation of the central hole is noticed, with principal axes about parallel and orthogonal to the bedding planes. The average convergence ranges from $3.8 \mathrm{~mm}$ in the direction of the bedding planes to $1.5 \mathrm{~mm}$ in the perpendicular direction. On the other hand, the small ovalisation of the outer boundary occurs in the other direction, i.e. a larger decrease in diameter is observed in the direction perpendicular to the bedding planes (average convergence of $0.8 \mathrm{~mm}$ ). These values were computed by contouring automatically the inner and outer boundaries of the hollow cylinders in the X-ray images taken before and after mechanical unloading (Fig. 4a, b), by calculating the displacements along the diameters parallel and perpendicular to the orientation of the bedding planes, and finally by averaging them over about 400 slices located in the central part of the specimen.

\subsubsection{B-BIS}

The experiment $\mathrm{N}^{\circ} 13 \mathrm{~B}$-BIS differs from $\mathrm{N}^{\circ} 13 \mathrm{~A}$ by the elapsed time between the second X-ray computed tomography and the mechanical unloading, i.e. 8 days (due to the unavailability of the X-ray machine). In the meantime, the inner confining pressure and inner drain pressure were kept constant at, respectively, 1,000 and $600 \mathrm{kPa}$ (i.e. inner radial effective stress equal to $400 \mathrm{kPa}$ ). Like for experiment $\mathrm{N}^{\circ} 13 \mathrm{~A}$, a clear convergence and ovalisation of the borehole are observed when comparing the CT scans before and after unloading (Fig. 7) and visually after the removal of the sample from the cell. The average displacement computed for about 300 slices ranges from $3.6 \mathrm{~mm}$ in the direction of bedding to $1.7 \mathrm{~mm}$ in the perpendicular direction.

The permeability was measured before and several times after the mechanical unloading. A small increase in hydraulic conductivity was found after the unloading (i.e. about $30 \%$ from $3.9 \pm 0.1 \times 10^{-12}$ to $4.9 \pm 0.1 \times 10^{-12} \mathrm{~m} / \mathrm{s}$ ), followed by a progressive recovery up to the initial value, i.e. $4.6 \pm 0.1 \times 10^{-12} \mathrm{~m} / \mathrm{s}$ after 1 week, $4.3 \pm 0.1 \times 10^{-12} \mathrm{~m} / \mathrm{s}$ after 2 weeks and $3.8 \pm 0.1 \times 10^{-12} \mathrm{~m} / \mathrm{s}$ after 3 weeks.

\subsection{Samples Cored Perpendicular to Bedding}

\subsubsection{4}

The experiment $\mathrm{N}^{\circ} 14$ on Boom clay aimed at studying the response for a sample taken perpendicularly to the bedding planes. Unfortunately, at the end of the in situ stress recovery stage, when bringing back the testing cell from the cantonal hospital where the X-ray tomography had been performed, oil from the inner confining circuit was found to leak into the inner drain circuit. As this leakage resulted in an almost equalisation of the inner confining and drain pressures and thus in a very low internal radial effective stress at the hole wall, the experiment was continued till the execution of a second X-ray tomography to get scans after the occurrence of the problem. In the meantime, the sample was kept under confining and drain pressures lower than the in situ conditions to prevent any further fluid exchange between the circuits. Figure 8 shows a slice of the sample before and after the leakage problem. 


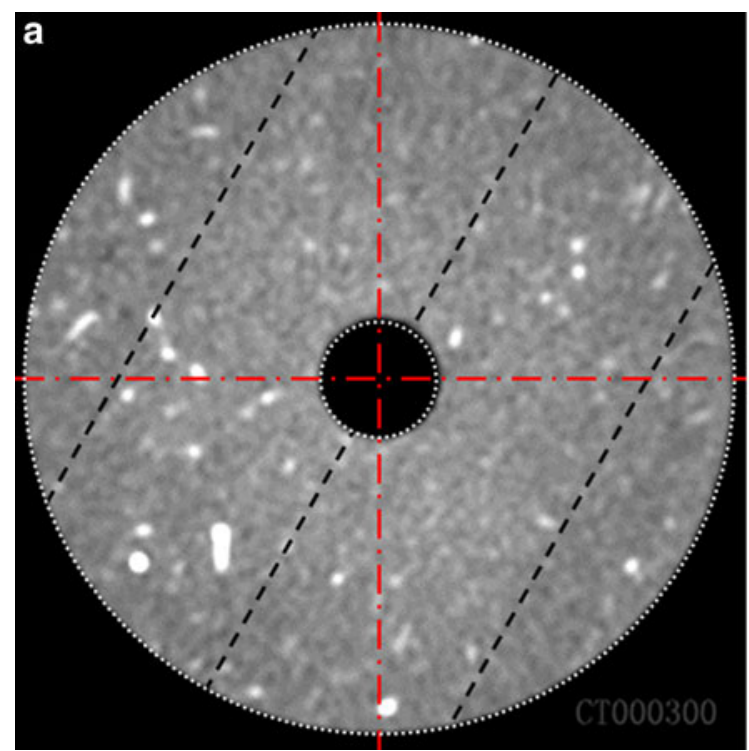

Fig. 6 Medium resolution XRCT scans of Boom clay $\mathrm{N}^{\circ} 13 \mathrm{~A}$ sample cored parallel to the bedding planes (schematically represented by the black dashed lines) before (a) and after (b) the mechanical unloading (same slice $\mathrm{N}^{\circ} 300$ as in Fig. 3). Clear oval-shaped deformation of the

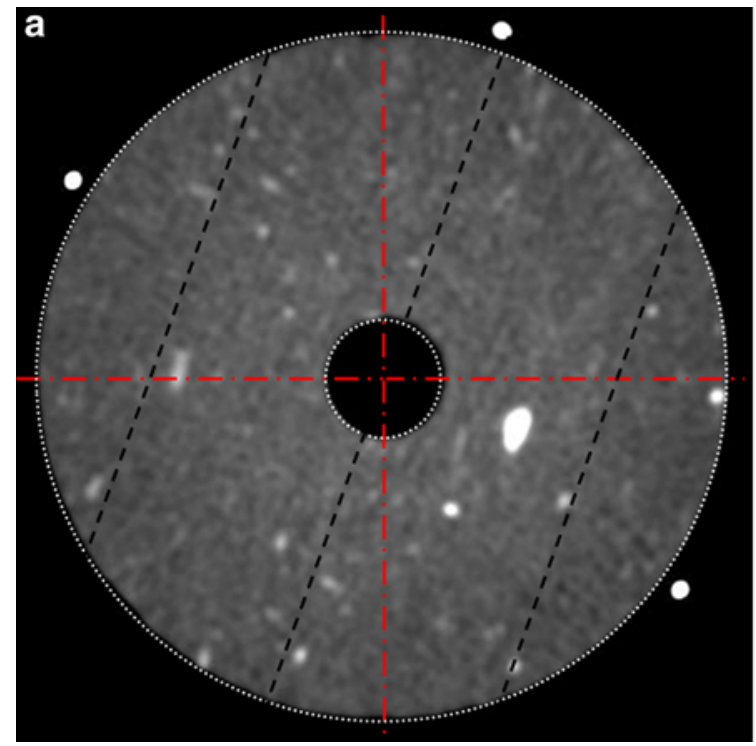

Fig. 7 Medium resolution XRCT scans of Boom clay $\mathrm{N}^{\circ} 13 \mathrm{~B}$-Bis sample cored parallel to the bedding planes (black dashed lines) before (a) and after (b) the mechanical unloading. Anisotropic

In contrast to the tests performed on specimens cored parallel to the bedding planes, no ovalisation is noticed and even no convergence is observed at the medical scanner resolution.

\section{$3.2 .214-B I S$}

The specimen used for the test $\mathrm{N}^{\circ} 14-\mathrm{BIS}$ was as well cored perpendicularly to the bedding planes in a block retrieved

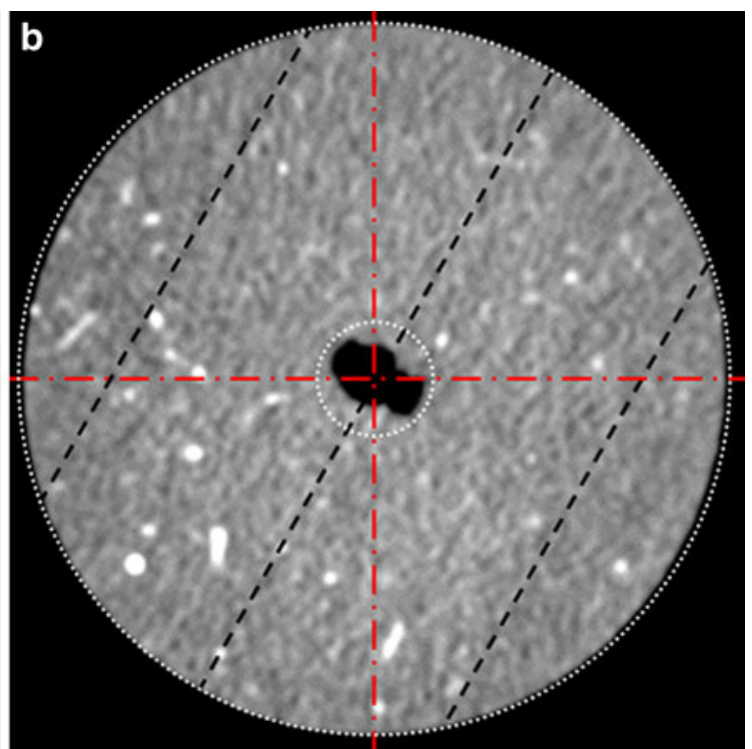

central hole (original diameter of $14 \mathrm{~mm}$ ) with principal axes parallel and perpendicular to bedding and small ovalisation of the outer boundary (diameter of $86 \mathrm{~mm}$ ) in the other direction. Images courtesy of Lausanne Cantonal Hospital (CHUV)

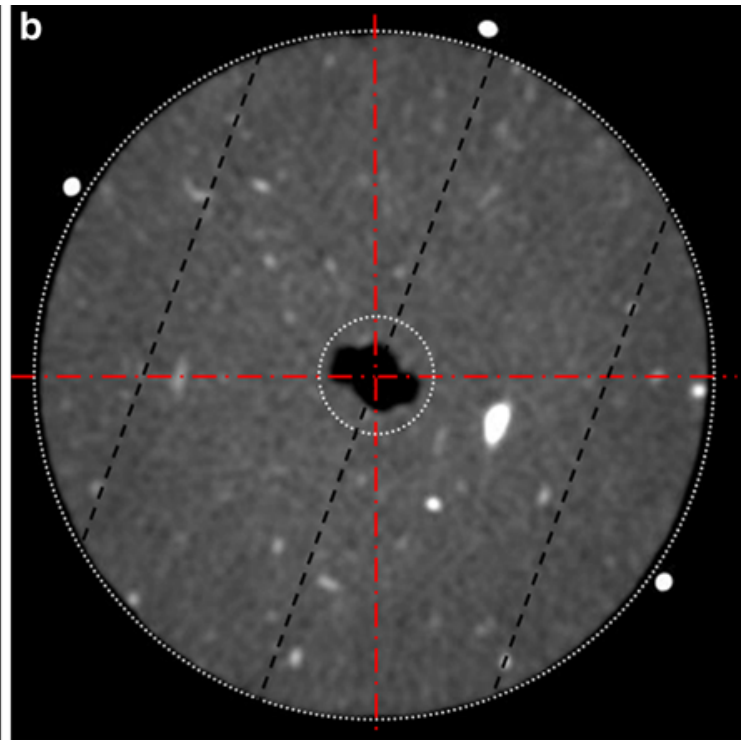

convergence of the central hole with symmetry axes parallel and perpendicular to bedding and of the outer boundary in the other direction. Images courtesy of Lausanne Cantonal Hospital (CHUV)

during the PRACLAY gallery excavation. Although it had a distinct fissure roughly parallel to its axis and crossing the central hole over the whole height (Fig. 9), a test was nevertheless performed, for lack of material. X-ray scans were carried out before the mechanical unloading (decrease in the borehole pressure from 4.5 to $1 \mathrm{MPa}$ ) and 7 days after it, the inner confining pressure and inner drain pressure being kept constant at, respectively, 1,000 and $100 \mathrm{kPa}$. After removal of the sample from the cell and saw 


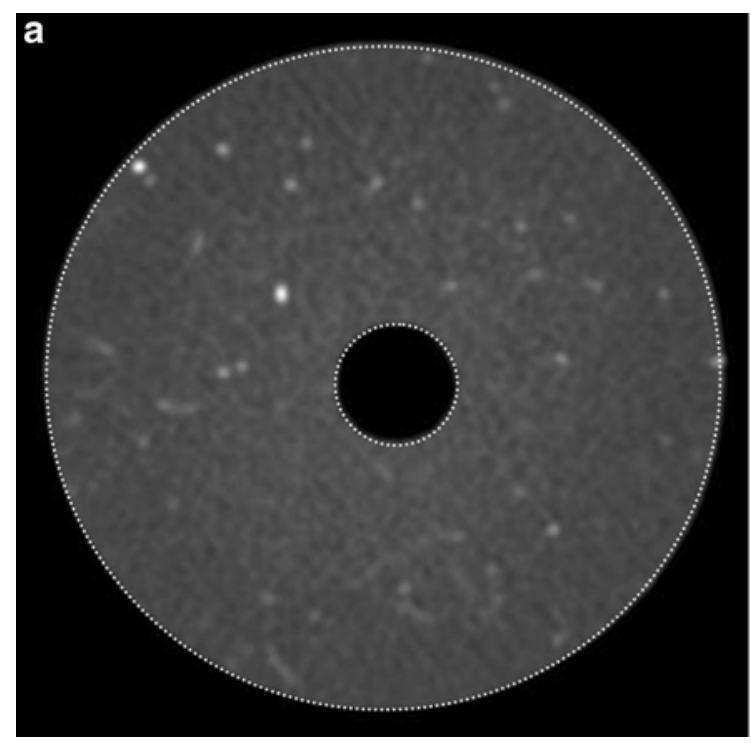

Fig. 8 Medium resolution X-ray scans of Boom clay $\mathrm{N}^{\circ} 14$ sample cored perpendicular to bedding, carried out through the testing cell before (a) and after (b) the occurrence of a leakage between the inner

cutting, the pre-existing fissure was discernible, but closed. An anisotropic convergence of the central hole, with symmetry axes in the pre-existing crack direction and in the perpendicular one, was clearly observed both visually and in the medium resolution X-ray tomography scans performed at the CHUV (Fig. 10). The convergence averaged over 350 slices ranges from $3.8 \mathrm{~mm}$ in the pre-existing crack direction to $1.5 \mathrm{~mm}$ in the perpendicular direction. A slight ovalisation of the sample is as well noticed in the CT scan after mechanical unloading, as in experiments $\mathrm{N}^{\circ} 13 \mathrm{~A}$ and $\mathrm{N}^{\circ} 13 \mathrm{~B}$ BIS. As for hydraulic conductivity measurements performed before and after the mechanical unloading, an increase of about $40 \%$ was observed, from $3.2 \pm 0.2 \times 10^{-12}$ to $4.4 \pm 0.1 \times 10^{-12} \mathrm{~m} / \mathrm{s}$ (average value for the whole specimen).

\subsection{Displacement Profiles}

Following the procedure explained in Sect. 2.4, quantitative analyses of the displacements inside the sample were performed by tracking in the $\mathrm{CT}$ images before and after mechanical unloading the movement of pyrite inclusions present in the clayey material. Figure 11 summarises the total displacement profiles along diameters parallel, perpendicular and at $45^{\circ}$ with respect to the bedding planes for experiments $\mathrm{N}^{\circ} 13 \mathrm{~A}$ and $\mathrm{N}^{\circ} 13 \mathrm{~B}-\mathrm{BIS}$ (upper and middle graphs) and with respect to the pre-existing crack for experiment $\mathrm{N}^{\circ} 14$-BIS (lower graph). The zigzags in the data somehow reflect the heterogeneity of the clay over the height of the sample and allow assessing the uncertainties of the displacement measurements to be around half a

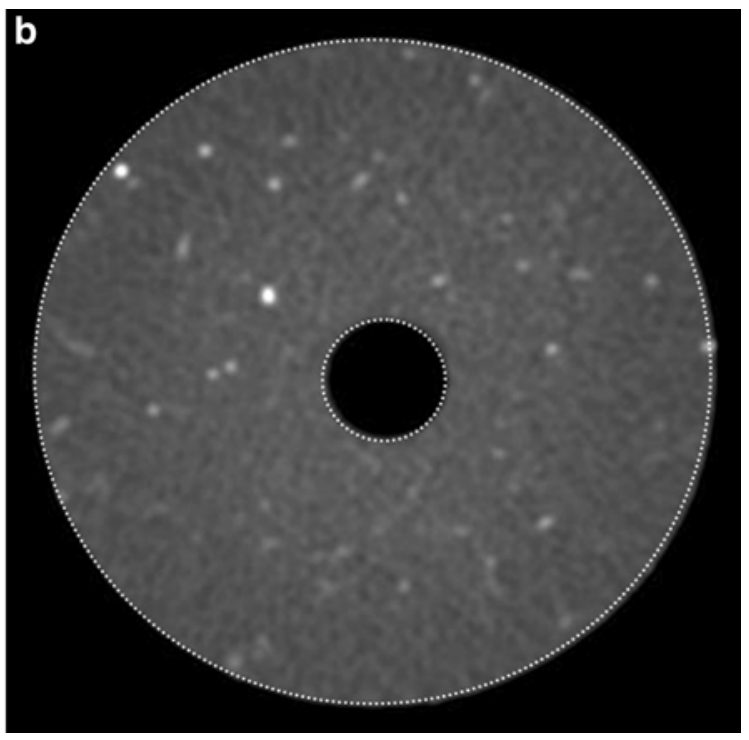

confining and hydraulic circuits (almost equalisation of pressures). No ovalisation is noticed. Images courtesy of Lausanne Cantonal Hospital (CHUV)

millimetre (the voxel size of the medical scanner being already of $0.215 \mathrm{~mm}$ ).

The displacement profiles plotted in the upper and middle graphs of Fig. 11 for respectively the experiments $\mathrm{N}^{\circ} 13 \mathrm{~A}$ and $\mathrm{N}^{\circ} 13 \mathrm{~B}-\mathrm{BIS}$ allow distinguishing a zone near the central hole with significant displacements (i.e. larger than $20 \%$ of the hole radius, namely $1.5 \mathrm{~mm}$ ) from another zone further inside the clay with lower and rather constant displacements. In the latter zone, the convergence is a bit larger in the direction perpendicular to bedding than in the direction parallel to bedding. In contrast, in the zone close to the hole, the convergence of the clay is significantly higher in the direction parallel to the bedding planes than in the perpendicular one. For instance, the displacement at the wall is equal to 3.8 and $1.5 \mathrm{~mm}$, respectively.

The displacement profile plotted for sample $\mathrm{N}^{\circ} 13 \mathrm{~A}$ in the bedding planes direction shows a slope discontinuity at a radius of $15 \mathrm{~mm}$, similarly to the sharp increase in displacement monitored in extensometers around underground structures which allows determining the portion of the rock mass that is damaged. By analogy with this terminology, the zone next to the central hole that is characterised by significant displacements will hereafter be referred to as "damaged zone". It extends $8 \mathrm{~mm}$ beyond the sidewalls in the bedding planes direction for sample $\mathrm{N}^{\circ} 13 \mathrm{~A}$. As for the 13B-BIS sample, the damaged zone extends further in the specimen in the direction of bedding (radius of $18 \mathrm{~mm}$ ) than in the perpendicular direction (radius of $12 \mathrm{~mm}$ ). It could actually have an eye shape (Fig. 12), as suggested by some observations at Mol URL in Boom clay (see Sect. 4.2). 
Fig. 9 Pictures before testing of Boom clay $\mathrm{N}^{\circ} 14-\mathrm{Bis}$ sample cored perpendicular to bedding in a block retrieved during the Praclay gallery excavation. It was characterised by a distinct fissure close to a diametrical plane
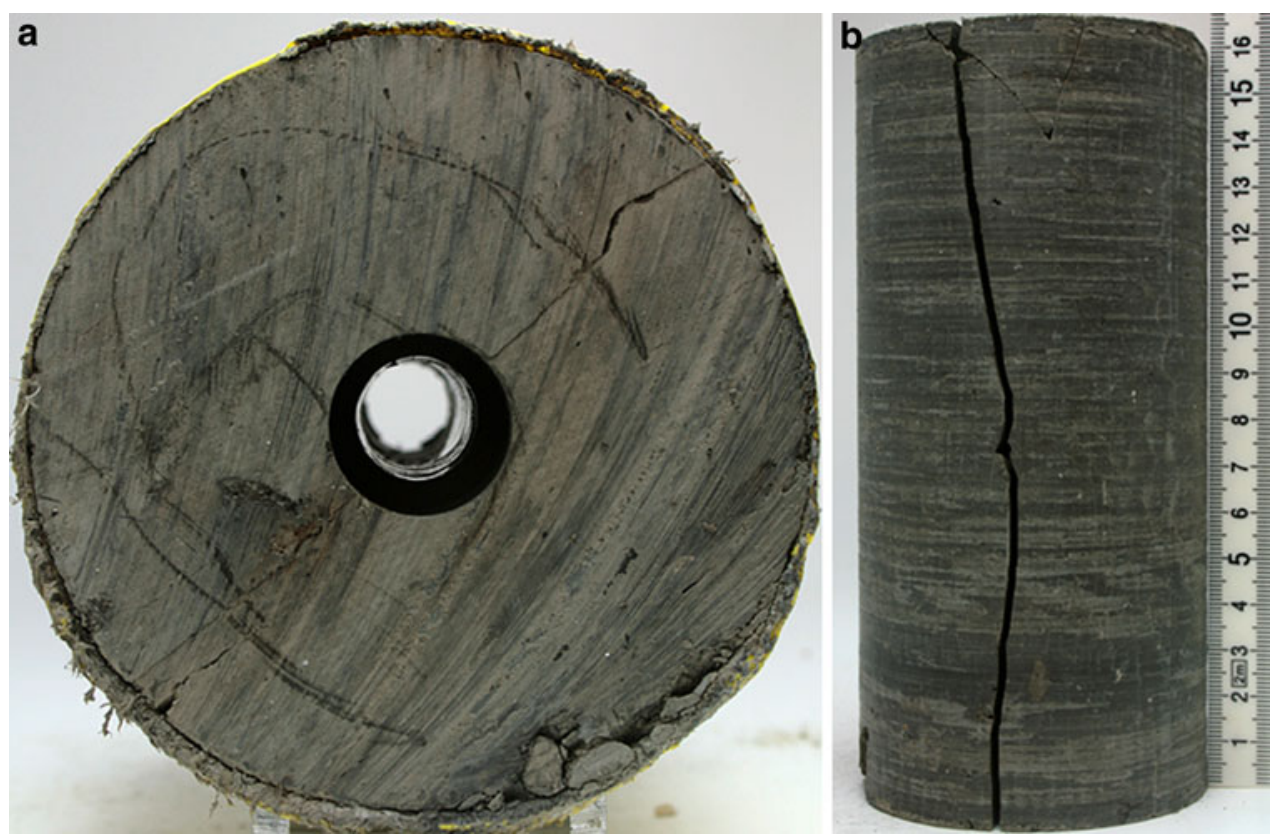

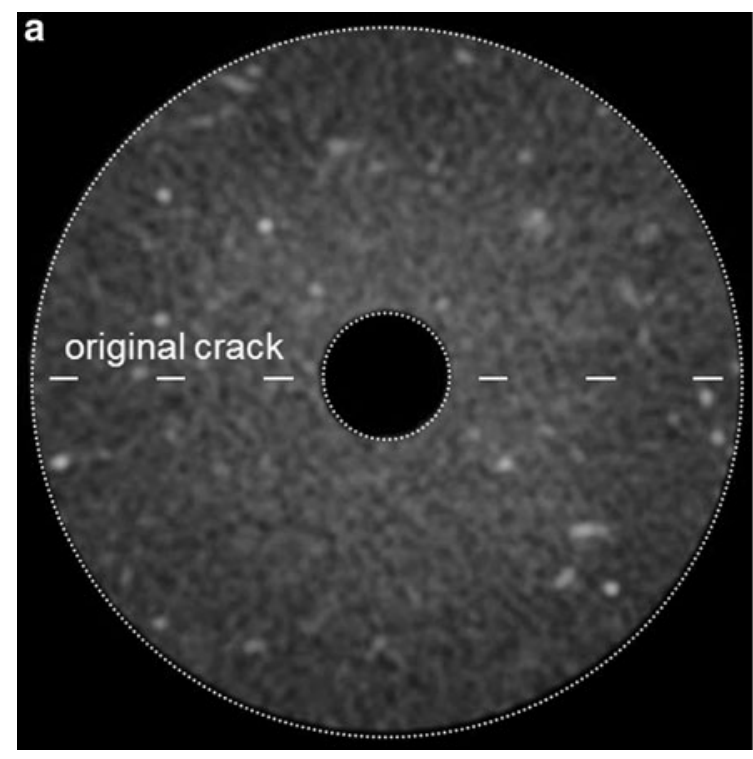

Fig. 10 Medium resolution XRCT scans before (a) and after (b) mechanical unloading of Boom clay $\mathrm{N}^{\circ} 14-\mathrm{Bis}$ sample cored perpendicular to bedding and characterised by a distinct fissure roughly located along a diametrical plane (schematically represented by the dashed line). Anisotropic convergence of the central hole with

A similar overall trend is observed in the lower graph of Fig. 11 plotted for the sample $\mathrm{N}^{\circ} 14-\mathrm{BIS}$ cored perpendicular to bedding, but with a pre-existing crack. At a certain distance of the central hole, the convergence is rather constant and a bit smaller in the pre-existing crack direction than in the perpendicular one. On the other hand, a reverse trend is noticed near the hole with displacements

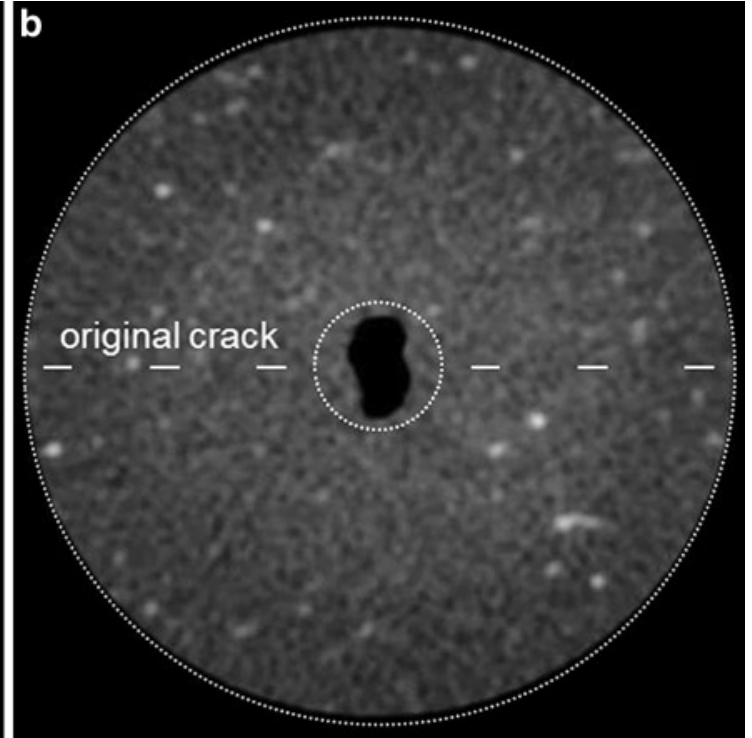

symmetry axes in the pre-existing crack direction and in the perpendicular one. Oval-shaped deformation of the outer boundary in the other direction. Images courtesy of Lausanne Cantonal Hospital (CHUV)

higher in the crack direction than in the perpendicular one. A change in behaviour is noticeable for a radius of about $13 \mathrm{~mm}$ in the displacement profile along the pre-existing crack direction, but is less evident in the two other directions. Again, an eye-shaped damaged zone seems to have developed around the hole, with a major axis in the direction of the crack. 

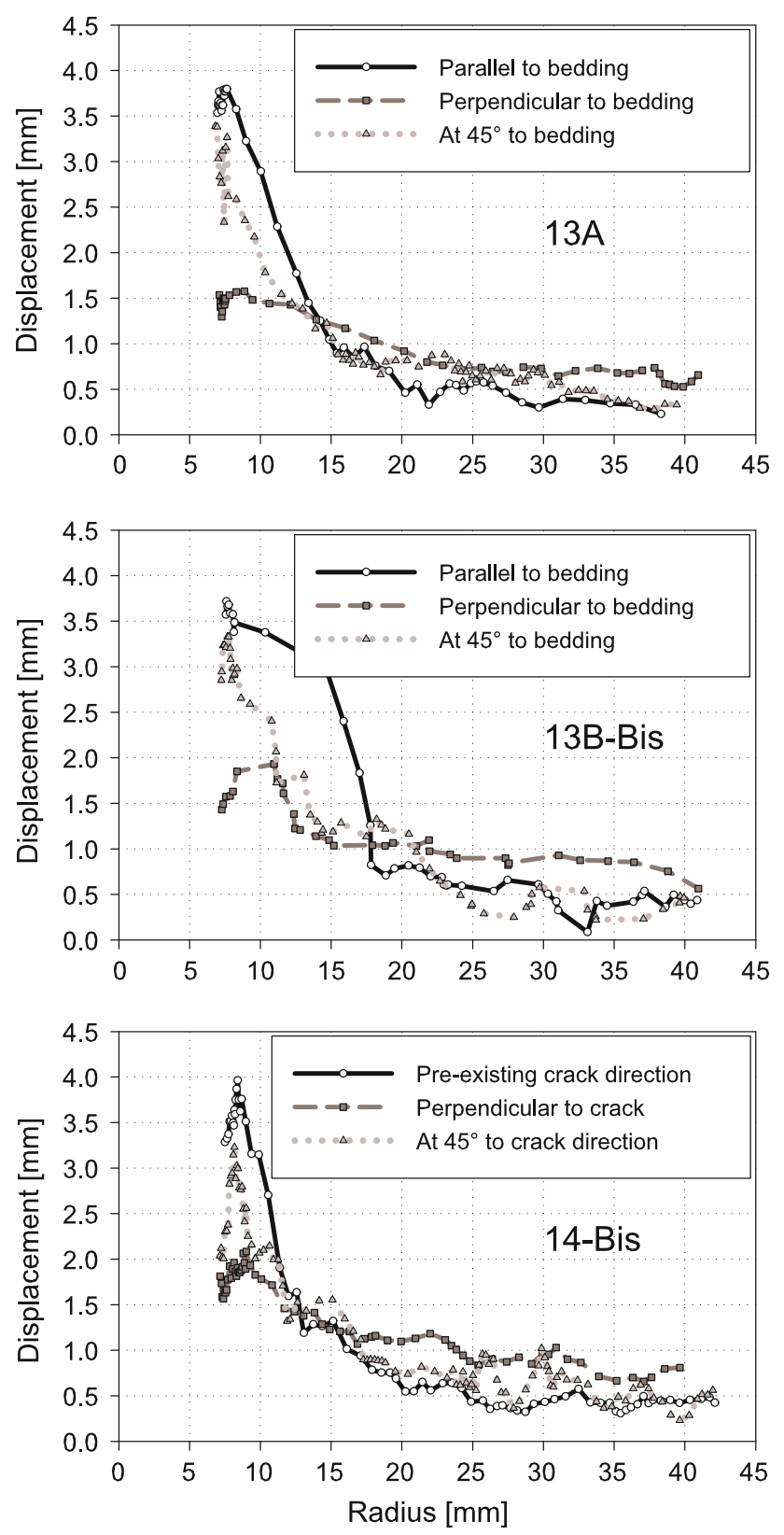

Fig. 11 Synthesis of the particle tracking analyses performed for the experiments $\mathrm{N}^{\circ} 13 \mathrm{~A}$ (upper graph), $\mathrm{N}^{\circ} 13 \mathrm{~B}$-Bis (middle graph) and $\mathrm{N}^{\circ} 14$-Bis (lower graph). Profiles of total displacement along diameters, respectively, parallel (black), perpendicular (dark grey) and at $45^{\circ}$ (light grey) to the weakness planes. These are the bedding planes in experiments $\mathrm{N}^{\circ} 13 \mathrm{~A}$ and $\mathrm{N}^{\circ} 13 \mathrm{~B}-\mathrm{Bis}$ and the pre-existing crack throughout the sample in experiment $\mathrm{N}^{\circ} 14$-Bis

\section{Discussion}

\subsection{Test Results}

Among the four tests, the only one which did not show any ovalisation and even convergence (at the medical scanner resolution) after the mechanical unloading is the experiment $\mathrm{N}^{\circ} 14$ carried out on a sample cored perpendicularly

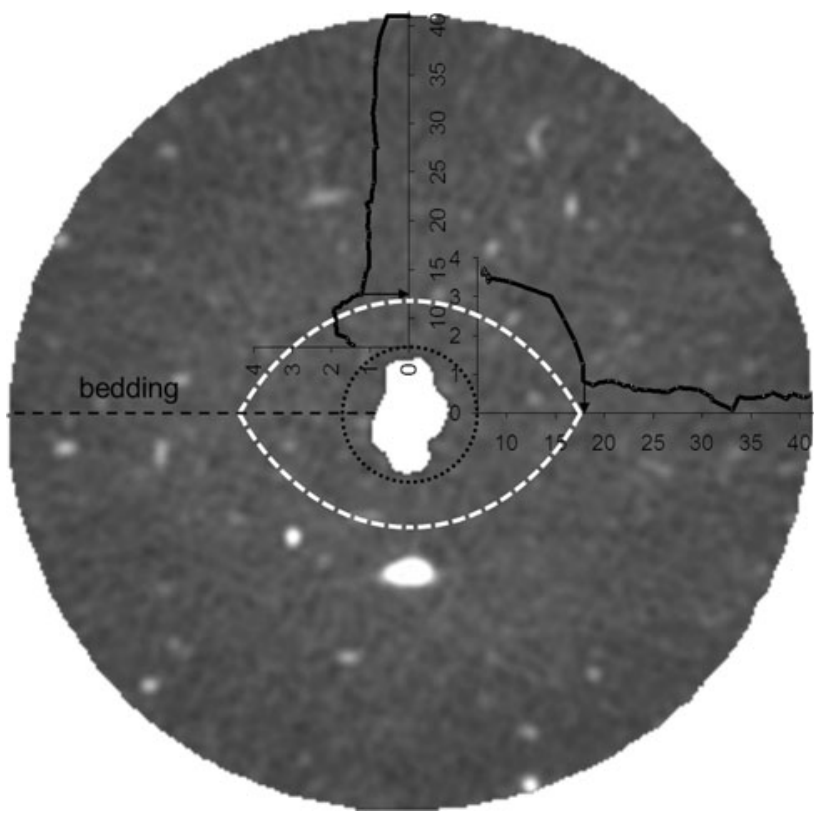

Fig. 12 Eye-shaped damaged zone around the central hole as inferred from the slope discontinuity observed in the displacement profiles along the diameters parallel, perpendicular and at $45^{\circ}$ to bedding (black dashed line). Experiment on sample $\mathrm{N}^{\circ} 13 \mathrm{~B}-\mathrm{Bis}$ cored parallel to the bedding planes

to the bedding planes. However, as the test did not run as expected, new experiments should be performed in the future to make sure that these observations are not affected by the leakage problem that occurred.

When compared with experiment $\mathrm{N}^{\circ} 14$, the three other hollow cylinder tests have clearly pointed out an anisotropic response to the mechanical unloading. A thorough comparison of these experiments leads to the following comments:

- The tests performed on the 13A and 13B-BIS samples differ in the time of XRCT scans after mechanical unloading, i.e. about $5 \mathrm{~h}$ for the former and 8 days for the latter. By comparing the results of the particle tracking analyses carried out for both tests (i.e. upper and middle graphs of Fig. 11), a further extension of the damaged zone and an increase in convergence are observed in the region surrounding the hole walls, especially in the direction parallel to bedding. As the drainage length of the hollow cylinders is short, this evolution can result from the redistribution of pore water pressures in the sample during the 8 days of drainage and to the related change in effective stresses. In this respect, as Boom clay is characterised by a hydraulic conductivity anisotropy ratio of about two, the faster diffusion of pore fluid along the bedding plane direction than perpendicular to it could as well contribute to the observed anisotropic displacements. 
- As the 14-BIS sample was cored perpendicularly to the bedding planes, one could have expected an isotropic response of the clay in cross sections and axisymmetric displacements. Surprisingly, features similar to the 13A and 13B-BIS experiments were observed after the mechanical unloading such as a strong "oval"-shaped (actually more like a peanut pod) deformation of the central hole and a slight ovalisation of the outer boundary in the other direction. This anisotropic response around the central hole is most probably related to the pre-existing crack in the sample which acts as a weakness plane with low cohesion, similarly to the bedding planes in the experiments on the $13 \mathrm{~A}$ and 13B-BIS samples cored parallel to bedding.

- As already pointed out, in the 13A and 13B-BIS experiments, the convergence further away from the central hole is found to be a bit larger in the direction perpendicular to the bedding planes than in the parallel one. This difference can partly be explained by the anisotropy of elastic properties of Boom clay, as the observed ratio of about two is in agreement with the ratio between Young's moduli in the directions parallel and perpendicular to bedding back-analysed from the ATLAS experiment at Mol (Chen et al. 2011). However, as similar displacements were measured for the 14-BIS sample that was cored perpendicular to bedding and had a pre-existing crack along a radial plane, the difference in convergences is actually mostly related to the development of an anisotropic damaged zone around the central hole and to the consequent redistribution of stresses.

- Finally, although the tests were performed on samples with different bedding orientations and the X-ray computer tomography scans were carried out at different times after the mechanical unloading, one can notice that the convergence at the hole wall is rather similar from one test to the other. Consequently, it has to be acknowledged that an experimental artefact is probably arising for large displacements of the central hole walls. Even if the inner neoprene membrane is thin $(1 \mathrm{~mm})$ and flexible, its low stiffness seems to be sufficient to influence and stabilise the convergence of the clay. An interesting analogy can be made between this observation and the stabilisation provided by thin shotcrete layers sprayed on tunnel walls, e.g. 10-20 cm for tunnels of about $5 \mathrm{~m}$ radius (Vietor T., personal communication).

In conclusion, the hollow cylinder test results emphasise the important mechanical anisotropy of Boom clay arising either from its natural bedded structure or from planar features (fissure throughout the 14-BIS sample) present before testing and the need for their correct consideration.
Such a result was to be expected, given that pre-existing planes of weakness are known to induce strength anisotropy and to influence the mode of failure of rocks. This was not evidenced in thick-walled hollow cylinders experiments on re-sedimented clays conducted by Chen et al. (1998) and Abdulhadi et al. (2011). Instead, among four tests performed on mudrock, Marsden et al. (1996) report the asymmetric behaviour of one sample and relate it to some heterogeneity or anisotropies in the microstructure of the material.

As concerns, the hydraulic conductivity measurements, the increase of about $30-40 \%$ found after mechanical unloading tends to confirm that a damaged zone with fractures has developed around the central hole. The subsequent progressive recovery up to the initial value observed in experiment $\mathrm{N}^{\circ} 13 \mathrm{~B}-\mathrm{BIS}$ is in agreement with laboratory and in situ experiments carried out in the framework of the SELFRAC project (Bernier et al. 2006; Blümling et al. 2007). Fractures developing in Boom clay seal actually very fast.

\subsection{In situ Observations}

In the hollow cylinder experiments performed on samples cored parallel to the bedding, the convergence of the central hole and the damage pattern that seems to develop around it when reducing the inner confining pressure are consistent with observations made during the construction of the connecting gallery and Praclay gallery at Mol URL (Bastiaens et al. 2003; Mertens et al. 2004; Blümling et al. 2007; Van Marcke and Bastiaens 2010):

- The fracturation pattern around the connecting gallery consists of conjugated shear planes. These fracture planes are curved. Their intersection with the vertical and horizontal planes passing through the gallery axis was found to be curved, but interestingly this curve is more pronounced vertically than horizontally. The excavation damaged zone (EDZ) is thus not symmetrical with respect to the gallery axis and extends a bit more in the horizontal plane (i.e. parallel to bedding), as confirmed in cores bored eastwards and downwards shortly after construction.

- The convergence of the walls observed in the unsupported zone between the shield and the lining is higher in the horizontal direction (parallel to bedding) than in the vertical direction (perpendicular to bedding). Over a portion of the gallery, a trimming of the sidewalls (10-20 $\mathrm{mm}$ of clay) was even necessary to place the lateral segments of the lining. Finally, though the steering of the shield did not present any particular difficulties, the vertical corrections in the steering were much easier than the horizontal ones. 
- In uncased boreholes drilled parallel to the bedding planes, an expulsion of clay pieces from the sidewalls (i.e. parallel to bedding) was revealed by camera observations and resin injection. It is related to the formation of conjugated eye-shape fractures. This type of fractures encountered around boreholes is possibly caused by the lack of support. The presence of such fractures around the connecting gallery is uncertain because it was lined almost immediately after excavation. However, in some sections, timber had to be placed between the hydraulic jacks of the tunnelling shield and the sidewalls to prevent large clay blocks coming off from the massif.

Less information is available for openings driven perpendicularly to bedding. However, large shear planes caused by the excavation of the second shaft that were observed during the construction of its foundations and of starting chambers were found to be symmetric around the shaft axis (Bastiaens et al. 2003; Mertens et al. 2004). Likewise, boreholes drilled in the vertical direction undergo a rather even convergence and do not show breakouts in preferential directions, contrary to those drilled horizontally (Adriaensen 2010). These observations corroborate the absence of anisotropic response noticed in experiment $\mathrm{N}^{\circ} 14$.

\subsection{Further Works}

Although the experiments carried out in the framework of the TIMODAZ project were already convincing, especially as concerns the similarity between laboratory and in situ observations, some improvements are foreseen to enhance the quality of the tests and the measurements: (1) achievement of a strict axial plane-strain condition during the mechanical unloading, (2) scans of the samples, insofar as possible, in a high-resolution X-ray scanner, (3) systematic use of image processing methods for the analysis of the X-ray tomography scans, such as the particle tracking of pyrite inclusions and 3D volumetric digital image correlation analysis.

Further hollow cylinder simulation experiments on Boom clay are still required to better describe and understand the failure mechanisms and the anisotropic fracture patterns that develop during the construction of galleries in this formation. A future experimental campaign should first duplicate the experiments performed in the TIMODAZ project to check the repeatability of the tests and assess the natural variability of the results. Then, by varying testing conditions (e.g. consolidation pressure, OCR, decrease and unloading rate of the inner confining pressure), experiments could contribute to investigate the development and the evolution of the excavation damaged zone (EDZ) for various disposal depths and construction techniques, towards an optimization of the support concept for nuclear waste disposal galleries.

\section{Conclusions}

In the context of nuclear waste disposal in clay formations, the Rock Mechanics Laboratory of the EPFL has performed laboratory experiments to study at reduced scale the excavation damaged zone (EDZ) induced by the construction of galleries in the Boom clay formation. For this purpose, thick-walled hollow cylindrical samples were subjected (after recovery of in situ stress conditions) to a decrease in the inner confining pressure aiming at mimicking a gallery excavation.

$\mathrm{X}$-ray computed tomography scans of the hollow cylinders were carried out in a medium resolution medical XRCT device before and after the mechanical unloading without removing the samples from the testing cell. Their comparison allowed a qualitative observation of the deformation undergone by the specimens as a result of the mechanical unloading. Moreover, thanks to the presence in the clayey material of pyrite inclusions that are well discernible in the CT scans, it was possible to perform quantitative analyses of the displacements inside the clay by using a particle tracking technique. The data were processed to determine the displacement profiles along diameters parallel, perpendicular and at $45^{\circ}$ with respect to bedding, allowing to evidence the anisotropic response of the clay related to its bedding planes.

The deformation of the hollow cylinders and the inferred extent of the damaged zone around the central hole are found to depend on the orientation of the specimen with respect to the bedding planes. In the experiments performed on samples cored parallel to the bedding, the damaged zone is not symmetrical with respect to the hole axis and extends more in the direction parallel to the bedding. It is the same for the radial convergence of the hole walls which is larger in the direction parallel to bedding than in the perpendicular one. In contrast, a test on a sample cored perpendicular to bedding did not show any ovalisation of the central hole after the mechanical unloading (at the medical scanner resolution, i.e. about $0.5 \mathrm{~mm}$ ). Another test on a specimen cored perpendicularly to the bedding planes, but with a distinct fissure roughly in a diametrical plane, did however show a strong anisotropic response of the hollow cylinder, with symmetry axes in the pre-existing crack direction and in the perpendicular one. This behaviour is most probably related to the pre-existing crack in the sample which acts as a weakness plane with low cohesion, similarly to the bedding planes in the experiments on samples cored parallel to bedding. 
The laboratory data are consistent with in situ observations made at Mol URL in the Boom clay formation, namely an anisotropic excavation damaged zone and convergence around horizontal galleries and boreholes (i.e. parallel to bedding), whereas the response is found to be isotropic for openings driven perpendicularly to the bedding (shafts and vertical boreholes). Such similarities of behaviour at the laboratory and in situ scales contribute to increase confidence in the understanding of the ongoing processes and in their modelling. They confirm the significance of the pre-existing planes of weakness (bedding planes) in Boom clay and the need for a correct consideration of the related mechanical anisotropy.

Acknowledgments The authors acknowledge the financial support provided by the European Commission for the TIMODAZ project performed as part of the sixth EURATOM framework programme for nuclear research and training activities (2002-2006) under contract FI6W-CT-2007-036449. They are grateful to Laurent Gastaldo (LMR-EPFL) for the experiments and to Martine Bernasconi of the Department of Diagnostic and Interventional Radiology of the CHUV (Lausanne Cantonal Hospital) for the X-ray computed tomography scans of the hollow cylinders. The third author also wishes to thank the China Scholarship Council (CSC) for the financial support provided for her stay at LMR-EPFL. The authors are also grateful to Joël Sarout (CSIRO) and to anonymous reviewer, whose suggestions and comments have helped to improve the quality of the paper.

\section{References}

Abdulhadi NO, Germaine JT, Whittle AJ (2011) Experimental study of wellbore instability in clays. J Geotech Geoenv Eng Am Soc Civil Eng 137(8):766-776

Adriaensen S (2010) Stageverslag, Euridice. Katholieke Universiteit Leuven, Belgium

Alsayed MI (2002) Utilising the Hoek triaxial cell for multiaxial testing of hollow rock cylinders. Int J Rock Mech Min Sci 39(3):355-366

Bastiaens W, Bernier F, Buyens M, Demarche M, Li XL, Linotte J-M, Verstricht J (2003) The connecting gallery-the extension of the HADES underground research facility at Mol, Belgium. Euridice report 03-294, Mol, Belgium, pp 98

Bernier F, Li XL, Bastiaens W, Ortiz L, Van Geet M, Wouters L, Frieg B, Blümling P, Desrues J, Viaggiani G, Coll C, Chanchole S, De Greef V, Hamza R, Malinsky L, Vervoort A, Vanbrabant Y, Debecker B, Verstraelen J, Govaerts A, Wevers M, Labiouse V, Escoffier S, Mathier J-F, Gastaldo L, Bühler Ch (2006)
SELFRAC: fractures and self-healing within the excavation disturbed zone in clays: final technical report EUR 22585. Commission of the European Communities, Luxembourg

Blümling P, Bernier F, Lebon P, Martin CD (2007) The excavationdamaged zone in clay formations-time-dependent behaviour and influence on performance assessment. Phys Chem Earth 32(5-14):588-599

Chen X, Tan CP, Wu B, Haberfield CM (1998) Modelling undrained behaviour of wellbores. In: The Geotechnics of Hard Soils-Soft Rocks, proceedings of the second international symposium on hard soils-soft rocks, Napoli, Italy, pp 483-489

Chen GJ, Sillen X, Verstricht J, Li XL (2011) ATLAS III in situ heating test in boom clay: field data, observation and interpretation. Comput Geotech 38(5):683-696

Ewy RT, Cook NGW (1990) Deformation and fracture around cylindrical openings in rock: II initiation, growth and interaction of fractures. Int $\mathrm{J}$ Rock Mech Min Sci Geomech Abstr 27(5):409-427

Haimson B, Kovacich J (2003) Borehole instability in high-porosity Berea sandstone and factors affecting dimensions and shape of fracture-like breakouts. J Eng Geol 69:219-231

Hoskins ER (1969) The failure of thick-walled hollow cylinders of isotropic rock. Int J Rock Mech Min Sci Geomech Abstr 6(1):99-116

Hosseini M, Rousseau C, Desrues J, Bésuelle P, Viggiani G (2006) Development of an experimental device to carry out tests on thick-walled hollow cylinders. In: Proceedings of Eurock 2006, ISRM reg symp, Liège, Belgium, pp 421-426

Labiouse V, Vietor T (2013) Laboratory and in situ simulation tests of the excavation damaged zone around galleries in Opalinus clay. Rock Mech Rock Eng. doi:10.1007/s00603-013-0389-4

Marsden JR, Dennis JW, Wu B (1996) Deformation and failure of thick-walled hollow cylinders of mudrock. A study of wellbores instabilities in weak rock. In: Proceedings of Eurock 96, ISRM reg symp, Torino, Italy, pp 759-766

Mertens J, Bastiaens W, Dehandschutter B (2004) Characterisation of induced discontinuities in the Boom clay around the underground excavations (URF, Mol, Belgium). Appl Clay Sci 26:413-428

Monfared M, Sulem J, Delage P, Mohajerani M (2011) A laboratory investigation on thermal properties of the Opalinus claystone. Rock Mech Rock Eng 44(6):735-747

Santarelli FJ, Brown ET (1989) Failure of three sedimentary rocks in triaxial and hollow cylinder compression tests. Int J Rock Mech Min Sci Geomech Abstr 26(5):401-413

Van Marcke P, Bastiaens W (2010) Excavation induced fractures in a plastic clay formation: observations at the HADES URF. J Struct Geol 32:1677-1684

You S, Labiouse V, Vigne L, Gastaldo L, Bernasconi M (2010) Medium resolution X-ray computed tomography of hollow cylindrical samples of Boom clay. In: Proceedings of Eurock 2010, ISRM reg symp, Lausanne, Switzerland, pp 755-758 